\title{
Spontaneous regression of metastatic pulmonary renal cell carcinoma in the setting of sarcomatoid differentiation of the primary tumour
}

\author{
Brian P.H. Chan, MD; ${ }^{*}$ Christopher M. Booth, MD, FRCSC; ${ }^{+}$Marosh Manduch, MD; Naji J. Touma, MD, FRCSC* \\ *School of Medicine, Queen's University, Kingston, ON; †Department of Oncology, Queen's University, Kingston, ON; §Department of Pathology and Molecular Medicine, Queen's University, Kingston, ON; \\ *Department of Urology, Queen's University, Kingston, ON
}

Cite as: Can Urol Assoc J 2013;7(9-10):e587-9. http://dx.doi.org/10.5489/cuaj.169 Published online September 10, 2013.

\section{Abstract}

We present a case of spontaneous regression of pulmonary metastases from renal cell carcinoma (RCC) with sarcomatoid differentiation, prior to intervention. The patient presented with conventional type RCC with Furhman Grade 4/4 and sarcomatoid differentiation, complicated by pulmonary metastases. Palliative systemic therapy was planned, but prior to the onset of treatment, serial computed tomography scans demonstrated regression of metastatic disease. Spontaneous regression of metastases is rare, but well-documented in conventional clear cell RCC. To the best of our knowledge, this has not previously been described in the setting of sarcomatoid differentiation of the primary tumour.

\section{Introduction}

Sarcomatoid differentiation is found in $1 \%$ to $5 \%$ of renal cell carcinoma (RCC) cases and is associated with poor outcomes due to rapid disease progression. ${ }^{1}$ Sarcomatoid differentiation is thought to represent a transition to higher histological grade and can be observed across all RCC subtypes. ${ }^{2}$ Prognostic factors for RCC include clinical stage, time to study entry, laboratory markers (LDH, HgB, Ca), sarcomatoid differentiation and number of sites of metastases..$^{2-5}$ The most common site of distant disease is pulmonary metastases. Due to its aggressive clinical course, sarcomatoid RCC is often treated with nephrectomy and systemic therapy, although there remains no consensus approach to treatment. The role of nephrectomy in the era of targeted therapy has yet to be fully elucidated. Spontaneous regression of metastases is well-documented in the course of conventional RCC, but not previously in the setting of sarcomatoid differentiation.

\section{Case report}

A 71-year-old male presented with an incidental finding of a large right renal mass on ultrasound during evaluation of the liver for hemochromatotis. Computed tomography (CT) scan (April 2010) revealed a $9.8 \times 8.9-\mathrm{cm}$ necrotic, heterogenous mass in the right kidney. Multiple nodules were identified in the lung parenchyma, the largest measuring $2.1 \mathrm{~cm}$ (Fig. 1, part A). The patient had been asymptomatic with no flank pain, hematuria, constitutional symptoms, bone pain or focal neurological symptoms. Medical history and physical examination were unremarkable.

His presentation was highly suggestive of RCC with metastatic involvement of the lungs. A repeat CT chest (May 2010) found the pulmonary nodules had increased in size, with the largest measuring $3.2 \mathrm{~cm}$ (Fig. 1, part B). Renal biopsy confirmed RCC. The patient was offered, but declined, nephrectomy. Based on the Memorial Sloan-Kettering prognostic factors model, ${ }^{5}$ the patient was intermediate risk, with one poor prognostic factor, anemia (HgB 136), and palliative sunitinib was planned. CT scans of the head and bone (June 2010) showed no brain or bone metastases, and metastases were limited to the lungs.

A repeat CT (July 2010) prior to the start of systemic therapy showed a radiologically stable RCC, and a decrease in size of pulmonary nodules (the largest lesion now $2.0 \mathrm{~cm}$ ). Given the apparent regression in disease and the lack of any clinical symptoms, systemic therapy was deferred and repeat CT planned. In October 2010, there was further decrease in size of the pulmonary nodules (the largest $0.7 \mathrm{~cm}$ ) and the primary tumour was unchanged (Fig. 1, part C).

Findings were consistent with regression of pulmonary metastatic disease. In November 2010, 6 months after the initial presentation, the patient underwent a laparoscopic radical nephrectomy, without complication.

Surgical pathology returned as T3a conventional type RCC with Fuhrman Grade 4/4 and sarcomatoid differentiation (Fig. 2). A CT scan in February 2011 showed further 

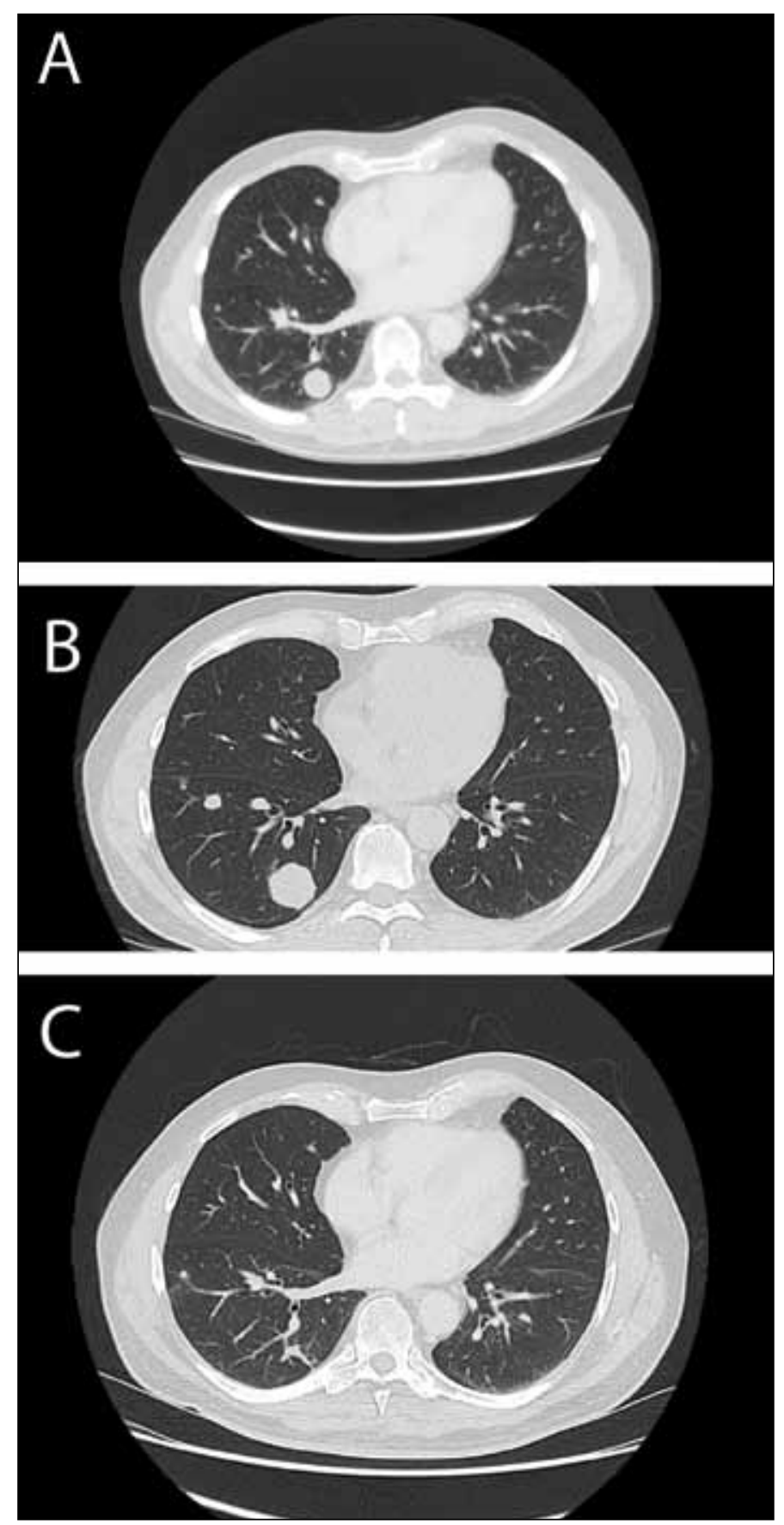

Fig. 1. Computed tomography scan demonstrating largest metastatic pulmonary nodule at (A) initial presentation $-2.1 \mathrm{~cm}$, (B) peak of growth $-3.2 \mathrm{~cm}$, and (C) regression $-0.7 \mathrm{~mm}$, in April, May and 0ctober 2010, respectively.

interval reduction in size of pulmonary nodules, consistent with regression of pulmonary metastatic disease. Surveillance scans at the 6- and 11-month follow-up remained stable, with no evidence of recurrence or progression of metastatic disease. Palliative systemic therapy was deferred and pulmonary nodules were too small for biopsy. The numerous sites of pulmonary metastases precluded metastasectomy.
In the absence of visible metastatic disease, the patient and oncologist elected not to proceed with sunitinib, as the benefit of therapy in this setting is not known. The patient was last seen in April 2012 and continues to do well clinically. The most recent CT (April 2012) revealed calcification of some pulmonary nodules, suggesting granuloma formation.

\section{Discussion}

Sarcomatoid differentiation of RCC has an aggressive clinical course, with poor overall prognosis and is characterized by rapid disease progression. Sarcomatoid differentiation is found in $1 \%$ to $5 \%$ of RCC, most commonly developing from clear cell or chromophilic RCC. ${ }^{1,6}$ In an analysis of 25 patients by Mian and colleagues, recurrent disease developed after a median time of 5.8 months in $80 \%$ of patients who underwent resection of initially localized disease. ${ }^{3}$ Among patients with advanced disease, the median survival ranges from 4 to 6 months.

RCC can have a highly variable clinical course, including spontaneous regression of metastases and an indolent course of metastatic disease. Spontaneous regression of pulmonary metastases in RCC is rare, occurring in less than $1 \%$ of all cases ${ }^{8}$ but has been noted since the first report by Bumpus in $1928 .{ }^{9}$ However, this has always been in the setting of conventional RCC. Regression of pulmonary metastases following nephrectomy has also been well-documented..$^{10-12}$ It is important to differentiate between spontaneous regression and regression following intervention. The current case demonstrates true spontaneous regression, with no medical or surgical intervention prior to metastatic disease regression. The pathogenesis of regression has not been elucidated, but activation of the host immune system has been implicated..$^{13}$

One limitation of our findings is a lack of tissue diagnosis from the pulmonary nodules seen on CT. Adequate histological demonstration of metastases has been estimated to be available in only $20 \%$ of cases with spontaneous regression. ${ }^{8}$ Several cases have been described wherein spontaneous regression of metastases from RCC was believed to have occurred but was not supported by biopsy histology. ${ }^{14,15}$ In one such case, pulmonary nodules showed no evidence of metastatic cells and were determined to be pulmonary infarcts. ${ }^{15}$ Given the documented initial growth pattern in the size of pulmonary metastasis in this case, this seems unlikely.

\section{Conclusion}

RCC is known to have a highly variable clinical course and spontaneous regression is well-described in conventional type RCC. We present the first known case of spontaneous regression of pulmonary metastases in the setting of RCC with sarcomatoid differentiation. 


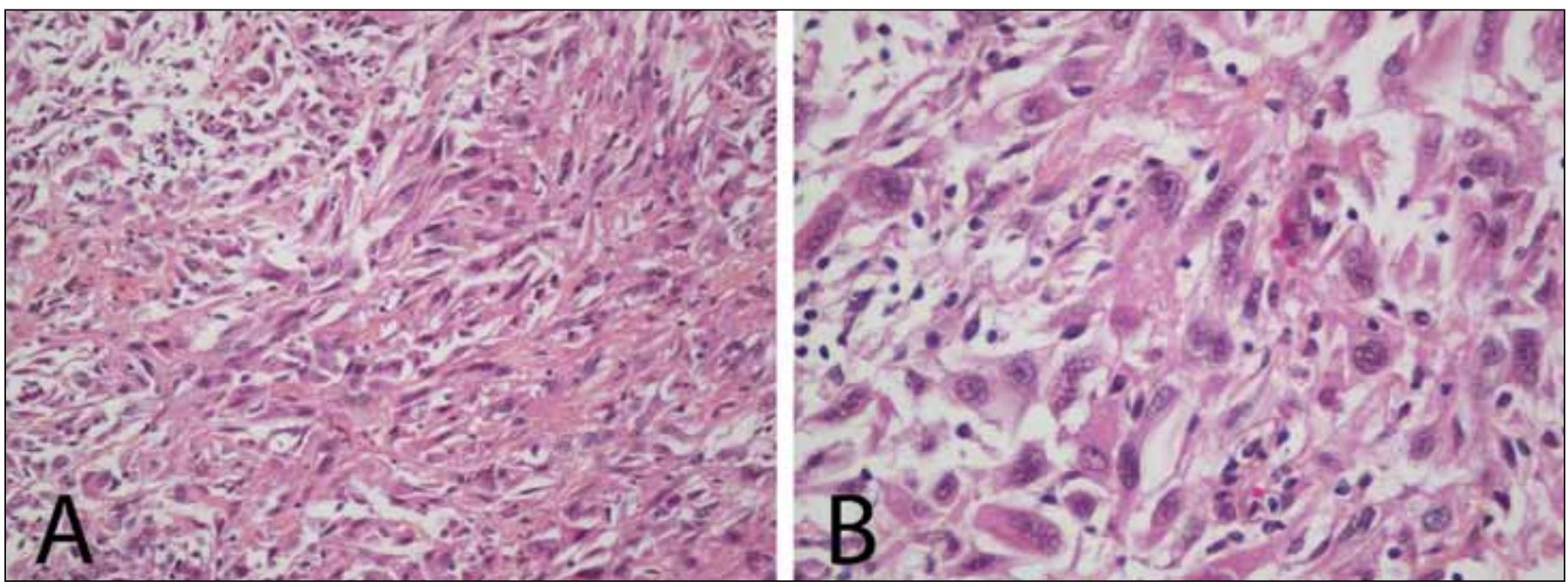

Fig. 2. Histological slides (hematoxylin phloxine saffron stain) at (A) 20x and (B) 40x magnification from surgical pathology, demonstrating sarcomatoid differentiation in the setting of renal cell carcinoma.

Competing interests: None declared.

This paper has been peer-reviewed.

\section{References}

1. Cheville IC, Lohse CM, Zincke H, et al. Sarcomatoid Renal Cell Carcinoma: An Examination of Underlying Histologic Subtype and an Analysis of Associations With Patient Outcome. Am I Surg Pathol 2004;28:43541. hittp://dx.doi.org/10.1097/00000478-200404000-00002

2. Lohse $C M$, Cheville JC. A Review of Prognostic Pathologic Features and Algorithms for Patients Treated Surgically for Renal Cell Carcinoma. Clin Lab Med 2005;25:433-64. http://dx.doi.org/10.1016/i. cll.2005.01.013

3. Mian BM, Bhadkamkar N, Slaton JW, et al. Prognostic factors and survival of patients with sarcomatoid renal cell carcinoma. J Urol 2002;167:65-70. http://dx.doi.org/10.1016/S0022-5347(05)65384-0

4. Golshayan AR, George S, Heng DY, et al. Metastatic Sarcomatoid Renal Cell Carcinoma Treated With Vascular Endothelial Growth Factor Targeted Therapy. J Clin Oncol 2009;27:235-41. http://dx.doi. org/10.1200/JC0.2008.18.0000

5. Mekhail TM, Abou-Jawde RM, Boumerhi G, et al. Validation and extension of the Memorial Sloan-Kettering prognostic factors model for survival in patients with previously untreated metastatic renal cell carcinoma. J Clin Oncol 2005;23:832-41. http://dx.doi.org/10.1200/JC0.2005.05.179

6. de Peralta-Venturina $M$, Moch H, Amin M, et al. Sarcomatoid Differentiation in Renal Cell Carcinoma: A Study of 101 Cases. Am J Surg Pathol 2001;25:275-84. http://dx.doi.org/10.1097/00000478200103000-00001
7. Dutcher JP, Nanus D. Long-term survival of patients with sarcomatoid renal cell cancer treated with chemotherapy. Med Oncol 2010;28:1530-3. http://dx.doi.org/10.1007/s12032-010-9649-2

8. Bos SD, Mensink HJ. Spontaneous caval tumor thrombus necrosis and regression of pulmonary lesions in renal cell cancer. Scand J Urol Nephrol 1996;30:489-92. http://dx.doi.org/10.3109/00365599609182329

9. Bumpus HC. The apparent disappearance of pulmonary metastasis in a case of hypernephroma following nephrectomy. J Urol 1928;20:185-91.

10. Lokich J. Spontaneous regression of metastatic renal cancer. Case report and literature review. Am I Clin Oncol 1997;20:416-8. http://dx.doi.org/10.1097/00000421-199708000-00020

11. Melichar B, Vaneckova J, Moravek P, et al. Spontaneous regression of renal cell carcinoma lung metastases in a patient with psoriasis. Acta Oncol 2009;48:925-7. http://dx.doi.org/10.1080/02841860902882451

12. Thoroddsen A, Gudbjartsson $T$, Geirsson $G$, et al. Spontaneous regression of pleural metastases after nephrectomy for renal cell carcinoma-a histologically verified case with nine-year follow-up. Scand I Urol Nephrol 2002;36:396-8. http://dx.doi.org/10.1080/003655902320783971

13. Schwaab T, Heaney JA, Schned AR, et al. A randomized phase II trial comparing two different sequence combinations of autologous vaccine and human recombinant interferon gamma and human recombinant interferon alpha2B therapy in patients with metastatic renal cell carcinoma: clinical outcome and analysis of immunological parameters. J Urol 2000;163:1322-7. http://dx.doi.org/10.1016/S0022$5347(05) 67771-3$

14. Hamid Y, Poller DN. Spontaneous regression of renal cell carcinoma: a piffall in diagnosis of renal lesions. J Clin Pathol 1998;51:334-6. http://dx.doi.org/10.1136/icp.51.4.334

15. Wagner JR, Merino MJ, Pass HI, et al. Pulmonary infarcts can mimic pulmonary metastases from renal cancer. J Urol 1997;158:1688-90. http://dx.doi.org/10.1016/S0022-5347(01)64096-5

Correspondence: Dr. Naii J. Touma, Kingston General Hospital, 76 Stuart St., Kingston, 0N K7L 2Vl; nitouma@gmail.com 